\title{
Survey of the contamination of eyedrops of hospital inpatients and recommendations for the changing of current practice in eyedrop dispensing
}

Moorfields Eye Hospital, City Road, London ECIV 2PD J D Stevens

\section{Institute of} Ophthalmology, Cayton Street, London EC1 M M Matheson

Correspondence to: J D Stevens, Moorfields Eye Hospital, City Road, London ECIV 2PD.

Accepted for publication 30 May 1991

\author{
J D Stevens, M M Matheson
}

variable growth of bacterial contaminants has been obtained. ${ }^{3-11}$ One study in an ophthalmic outpatient clinic found tear contamination of eye-dropper bottles, ${ }^{12}$ and a number of studies have commented on the inhibition of growth of bacteria by preservatives. The survival of organisms has been found in the bottle dead space and cap. ${ }^{13-15}$

There has been improvement in the efficacy of preservatives used in eyedrop preparations, ${ }^{131416-18}$ and modern multidrop bottles may be expected to have a very low level of contamination with viable bacterial organisms. To test the efficacy of antimicrobial presevative the British Pharmacopoeia Commission set up a working party in 1988 to study multidose ophthalmic products. Eyedrops were selected owing to their differing preservatives, their initial sterility, and their frequency of use. ${ }^{19}$ Four different preparations were studied, and contamination was found in 5\% of 604 samples. Only low levels of contamination were generally found, with higher levels restricted to a few samples containing coagulase-negative staphylococci.

In the United Kingdom it is policy that unidrop dispensers are used for external disease clinic outpatients and all patients for a casualty department owing to the fear of infection. ${ }^{20}$ Multidrop bottles should not be used in these areas. Currently Moorfields Eye Hospital use multidrop bottles for outpatient clinics and wards. Unidrop dispensers are used for the casualty department and external eye disease patients.

\section{Material and methods}

SPECIMENS COLLECTED

One hundred and forty three multidrop bottles from postoperative, routine, non-infected, cataract and trabeculectomy patients were assessed. The eyedrops were prepared in Moorfields Eye Hospital Pharmacy Department and issued for use in amber glass bottles. Screw

Table 1 Eyedrops from postoperative routine patients

\begin{tabular}{llr}
\hline Dexamethasone $0 \cdot 1 \%$ & $(0 \cdot 005 \%$ Thiomersal $)$ & 80 \\
Cyclopentolate $1 \%$ & $(0 \cdot 01 \%$ Benzalkonium chloride $)$ & 38 \\
Prednisolone $1 \%$ & $(0 \cdot 01 \%$ Benzalkonium chloride $)$ & 16 \\
Phenylephrine $10 \%$ & $(0 \cdot 01 \%$ Benzalkonium chloride) & 2 \\
Prednisolone 0.3\% & $(0 \cdot 01 \%$ Benzalkonium chloride) & 2 \\
Timolol 0.25\% & $(0 \cdot 01 \%$ Benzalkonium chloride) & 2 \\
Cyclopentolate $1 \%$ & (Without preservative) & 1 \\
Adrenaline 0.1\% & (Without preservative) & 1 \\
Atropine $1 \%$ & $(0 \cdot 01 \%$ Benzalkonium chloride) & 1 \\
Total & & 143 \\
Number contaminated & & 0 \\
\hline
\end{tabular}


caps are fitted with integral glass droppers. These bottles were used for one or two days by a single patient and then discarded on discharge of the patient from hospital. In each case the patient subsequently received identical multidrop bottles to take home. No multidrop bottles were examined that had been used for more than 72 hours on the ward. After collection, the contents of the bottles were immediately taken for bacterial culture.

We also examined 216 bottles from outpatient areas of the hospital in an identical way. These bottles have been used for eyedrop application to different patients during one clinic session before being discarded. Bottles were collected for bacterial culture at the end of the clinic session.

\section{BACTERIAL CULTURE}

Approximately $0.5 \mathrm{ml}$ of each solution was cultured in $20 \mathrm{ml}$ of thioglycollate (Brewer) broth (Fig 2). This not only acts as an enrichment medium, but helps to dilute out any antibacterial effect of the preservative in the dropper bottles. After 24 hours incubation in $\mathrm{CO}_{2}$ at $37^{\circ} \mathrm{C}$ the broth was examined for bacterial growth. Each broth was then subcultured on blood agar in aerobic conditions and again incubated for the same period. These plates were then examined for any growth, and any pathogens were identified. All thioglycollate broth cultures were subsequently examined at 10 days. The anaerobic bottle with thioglycollate broth supported growth of Pseudomonas as well as sporing and non-sporing anaerobes. The combination of Brewer broth and the agar plates allowed a very wide spectrum of organisms to be cultured.

\section{Results}

Dropper bottles used by 143 postoperative patients were cultured and none were found to be contaminated (Table 1). Two hundred and sixteen bottles used in the out-patient area were taken, and five bottles grew organisms (Table 2). A light growth of Staphylococcus epidermidis grew from one bottle of cyclopentolate $1 \%(0.01 \%$ benzalkonium chloride preservative), and a mixed growth of Staphylococcus aureus and Staph epidermidis was obtained from four bottles of phenylephrine $10 \% \quad(0.01 \%$ benzalkonium chloride preservative).

For the outpatient multidrop bottles 149 used benzalkonium chloride as preservative. All five contaminated bottles had benzalkonium chloride as preservative, giving a $3 \cdot 4 \%$ contamination rate for this preservative. The overall contamination rate was $\mathbf{2 \cdot 3} \%$ for all out-patient bottles.

\section{Discussion}

OUTPATIENT AND MULTIDROPS

The $2 \cdot 3 \%$ contamination rate of the outpatient dropper bottles is consistent with the findings in previous studies. ${ }^{3-11} 19$ The differing incidences of contamination recorded in other studies may be partly due to differences in procedures and microbiological methods rather than true dif-

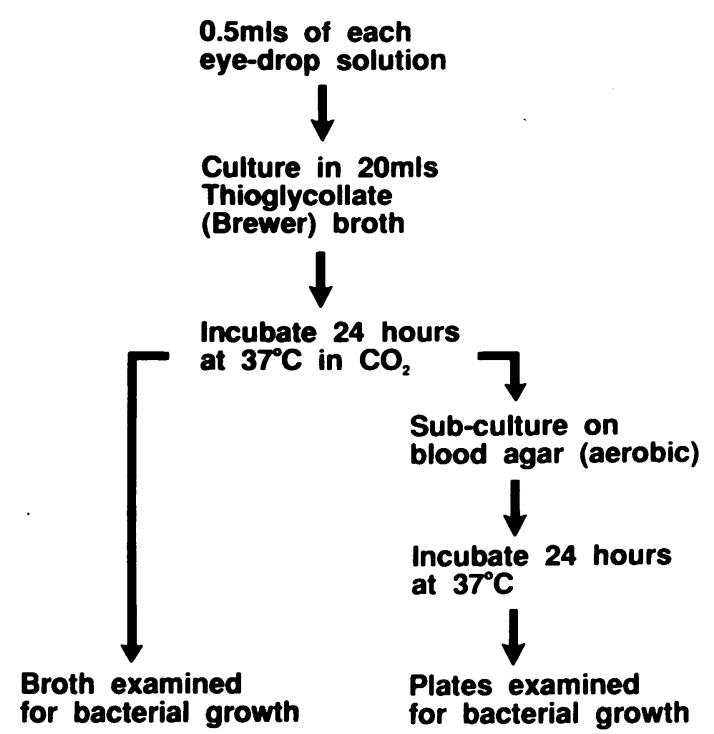

Figure 2 Method for culture of eyedrops.

ferences in incidence. ${ }^{19}$ Whether there is a difference in preservative efficacy was not addressed in this study, but it is interesting that the five contaminated bottles all used benzalkonium chloride as the preservative. The study of the British Pharmacopoeia Commission found that samples with relatively high bacterial counts were those from bottles preserved with thiomersal, ${ }^{19}$ and the continued use of thiomersal in eyedrops has been questioned. ${ }^{3}$ We have not found contamination in thiomersal preserved bottles, but in our study only 13 bottles using this preservative were collected from the outpatient clinics. Whichever preservative is used, multidrop dropper bottles are known to be a vector for potential contamination from one patient to another ${ }^{12}$ and care should be exercised in the drop application technique.

The use of multidrop bottles in outpatient areas where a bottle is used for different patients is potentially a source of interpatient contamination. Ideally only unidrop disposable eyedrop containers would be used, but they can cost more than multidrop bottles. For any patient that might be infected or have external eye disease a unidrop dispenser should be used. Alternatively the multidrop bottle could be discarded after use with an infected or potentially infected patient. We have not recorded if some of the bottles in this study were discarded by clinic staff after such use.

Table 2 Eyedrops from the outpatient clinic area

\begin{tabular}{|c|c|c|}
\hline $\begin{array}{l}\text { Cyclopentolate } 1 \% \\
\text { Phenylephrine } 10 \% \\
\text { Benoxinate } 0 \cdot 3 \% \\
\text { and fluorescein } 0 \cdot 125 \% \\
\text { Pilocarpine } 2 \% \\
\text { Tropicamide } 1 \% \\
\text { Amethocaine } 1 \% \\
\text { Tropicamide } 1 \% \\
\text { Isotonic saline } \\
\text { Benoxinate 0·4\% } \\
\text { Eserine 0.5\% } \\
\text { Atropine } 1 \% \\
\text { Phenylephrine 5\% } \\
\text { Cocaine 4\% } \\
\text { Total } \\
\text { Number contaminated }\end{array}$ & $\begin{array}{l}\text { (0.01\% Benzalkonium chloride) } \\
\text { (0.01\% Benzalkonium chloride) } \\
\text { (0.004\% Phenylmercuric nitrate) } \\
\text { (0.01\% Benzalkonium chloride) } \\
\text { (0.01\% Benzalkonium chloride) } \\
\text { (0.002\% Phenylmercuric nitrate) } \\
\text { (0.01\% Benzalkonium chloride) } \\
\text { (0.005\% Thiomersal) } \\
\text { (0.01\% Chlorhexidine acetate) } \\
\text { (0.01\% Benzalkonium chloride) } \\
\text { (0.01\% Benzalkonium chloride) } \\
\text { (0.01\% Benzalkonium chloride) } \\
\text { (0.002\% Phenylmercuric nitrate) }\end{array}$ & $\begin{array}{r}46 \\
42 \\
28 \\
21 \\
19 \\
15 \\
15 \\
13 \\
10 \\
2 \\
2 \\
2 \\
1 \\
216 \\
5\end{array}$ \\
\hline
\end{tabular}




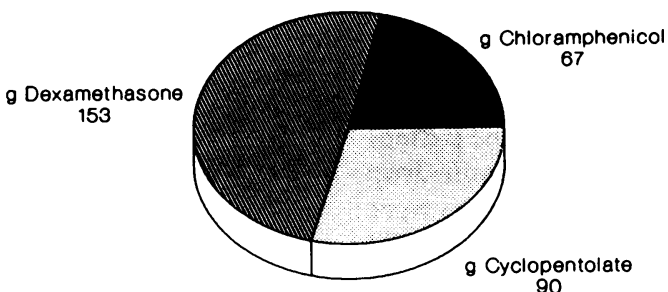

Figure 3 Cost of postoperative eyedrops (pence). From British National Formulary, 1989

\section{INPATIENT DROPS}

For inpatient use the current practice in the UK is for each patient to have a set of postoperative medications while in hospital and a duplicate set to take home. ${ }^{19}$ This practice has not changed since the time that patients entering an ophthalmic ward and receiving surgery routinely stayed for many days postoperatively. Almost always those drugs to take home are identical to those prescribed for use on the ward. Modern practice has resulted in shorter inpatient stay, and an increasing proportion of patients undergo ophthalmic surgery as day cases.

In the interests of infection control each inpatient has their own set of drops while on the ward. Usually this comprises a topical steroid, an antibiotic, and in some cases a dilating drop. At present the postoperative stay in hospital is routinely one or two days,,$^{12}$ and a bottle of drops lasts up to one month. On the ward, often, only one or two drops are used before the bottle is then discarded as the patient is discharged.

We did not find any bacterial contamination of inpatient postoperative eyedrops for cataract and trabeculectomy patients. For these routine, noninfected, short-stay patients we propose that, to save costs and to increase efficiency, medical staff should prescribe postoperative drops at the postoperative ward round, and patients should use them both on the ward and to take home, provided the bottle has not been open for longer than 72 hours. Since this study has reviewed postoperative contamination only for short-stay patients, we cannot exclude contamination of bottles opened for longer periods of time.

Not replacing the postoperative eyedrops used on the ward and allowing patients to take the same bottles home would reduce postoperative drug costs by up to $50 \%$ (Fig 3 ). There would also be a reduction of work load for ward, medical, and pharmacy staff. Mistakes and omissions should also decrease. Patients on being discharged do not have to wait for their drops to arrive from the hospital pharmacy, and can leave hospital much quicker, so vacating a bed sooner.

On admission to hospital, instruction is given by nursing staff in technique of instillation. By dispensing the same drops on the ward as will be used at home, the time in hospital allows patients to practice instilling the same drops. Patients would not become confused by a different brand of eyedrop being dispensed just prior to leaving hospital.

We acknowledge with thanks the help of $\mathrm{Mr} \mathrm{V}$ Andrews, principal pharmacist, Moorfields Eye Hospital, and Miss J Bloom, staff pharmacist, Moorfields Eye Hospital.

1 Department of Health and Social Security Health Services. Costing Returns Year Ended 31 March 1987. ISBN 185197 363 X. 19-35.

2 Number of extractions and duration of stay. Hospital in-patien enquiry 1979-1985. London: HMSO, Series MB4 no. 29: enquiry

3 Ford JL, Brown MW, Hunt PB. A note on the contamination of eye-drops following use by hospital out-patients. $\mathcal{F}$ Clin Hosp Pharm 1985; 10: 203-9.

4 McIntyre DJ. More on contamination of solution. Ophthalmi Surg 1984; 15: 534

5 Yolton DP, German CJ. Fluress, fluorescein and benoxinate recovery from bacterial contamination. $\mathcal{F}$ Am Optom Assoc 1980; $51: 471-4$.

6 Aslund B, Olson OT, Sandell E. Studies on in-use microbial contamination of eye drops. Acta Pharm Suec 1978; 15: 389 94.

7 Marion AD, Tapert MJ. Bacterial contamination of timolol in use by a non-selected clinic population. ARVO Abstracts. Invest Ophthalmol Vis Sci supplement. Philadelphia: Invest Ophthalmol

8 Schein OD, Wasson PJ, Boruchoff SA, Kenyon KR Microbia keratitis associated with contaminated ocular medications.

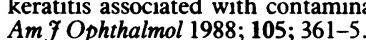

9 Hugo WB, Wilson JV. In-use contamination of eye-drops. Pharm F 1970; 204: 714.

10 Hugo WB, Wilson JV. A survey of in-use contamination of eye-drops. F Hosp Pharm 1970; 28: 258-62.

11 Olszewsk Z, Michalewska J, Krutul H, Scimborska L. Effect of preservatives on the survival of Staphylococcus aureus and Pseudomonas aeruginosa in eyedrops containing antibiotics. Acta Pol Pharm 1976; 33: 643-51.

12 Aylward GW, Wilson RS. Contamination of dropper bottles with tear fluid in an ophthalmic outpatient clinic. $\mathrm{Br} \mathrm{Med} \mathscr{f}$ 1987; 294: 1587.

13 Hovding G, Sjursen $\mathbf{H}$. Bacterial contamination of drops and dropper tips of in-use multidose eye drop bottles. Acta dropper tips of in-use multidose

14 Coad CT, Osato MS, Wilhelmus KR. Bacterial contamination of eyedrop dispensers. Am $\mathcal{F}$ Ophthalmol 1984; 98: 548-51.

15 Templeton WC 3d, Eiferman RA, Snyder JW, Melo JC, Raff MJ. Serratia keratitis transmitted by contaminated eyeMJ. Serratia keratitis transmitted by cont
droppers. Am $\mathcal{F}$ Ophthalmol 1982; 93: 723-6.

16 Preservation of eye-drops. (Editorial.) Pharm $\mathcal{F}$ 1964; 192 587-8.

17 Stewart HL. Prolonged antibacterial activity of fluorescein anaesthetic solution. Arch Ophthalmol 1972; 88: 385-7.

18 Du Bois SK, Pinney RJ, Davison AL. Investigation of the levels of bacterial contamination in used eye drops. Poster presentation, British Pharmaceutical Conference, Keele 1989.

19 Davison AL, Hooper WL, Spooner DF, Farwell JA, Baird R. The validity of the criteria of pharmacopoeial preservative efficacy tests - a pilot study. Pharm f 1991; 246: 555-7.

20 Preservation of sterility in ophthalmic preparations in hospitals. reservation of sterility in ophthalmic preparations in hospitals. Department of Health and Social Security UK 